\title{
PRESENTACIÓN
}

\section{De dineros, crisis y sobreendeudamientos}

\author{
Magdalena Villarreal
}

$\mathrm{L}$ a rabia contra la maquinaria capitalista se ha desatado en distintos puntos del planeta. Desde Seattle hasta Sídney los manifestantes toman las calles: los Indignados en España, el movimiento por la Ocupación de Wall Street en Estados Unidos y los griegos inconformes por las excesivas medidas de austeridad impuestas en su país. Miles de afectados vociferan ante la falta de empleos, la creciente inequidad social y la excesiva influencia corporativa sobre la democracia, del sector financiero en particular. Los participantes en estos movimientos declaran formar parte del $99 \%$ de la población que está pagando los pecados de una minoría.

El coraje encuentra eco en millones de ciudadanos del mundo. Tanto jóvenes como gente mayor se enfrentan a salarios disminuidos y pensiones recortadas. La inflación se traga el valor de los ahorros de quienes tuvieron un empleo estable, mientras que un gran contingente no puede siquiera encontrar trabajo. La crisis que azota buena parte del globo es tema de constante preocupación en diversos sectores. En ésta - aunque no únicamente debido a ella- el endeudamiento y el sobreendeudamiento han mostrado sus múltiples caras. Sabemos, como se informa cotidianamente en los medios de comunicación, que afecta tanto a países primermundistas como a los considerados subdesarrollados y a todos los sectores sociales. Sin embargo, las maneras en que impacta a las poblaciones de bajos recursos tienden a estimarse con base en caracterizaciones estereotipadas de los pobres, quienes se presumen financieramente inactivos.

El endeudamiento en los sectores de bajos ingresos de la población mundial no es nuevo, pero la creciente financiarización en el contexto de la recesión mundial genera nuevos riesgos: fue creciendo a un ritmo acelerado, impulsada por la baja rentabilidad de los sistemas productivos frente a los jugosos dividendos obtenidos en el sector financiero y con la complicidad de decisiones políticas deliberadas en apoyo a la desregulación. El afán de obtener mayores ganancias de inversiones financieras llevó a una expansión de la oferta de dinero, mercancías y servicios financieros a sectores cada vez más amplios.

\section{On Monies, Crises and Overindebtedness}

\author{
Magdalena Villarreal: Centro de Investigaciones y Estudios Superiores en Antropología Social-Occidente, \\ Guadalajara, Jalisco, México \\ magdalena.villarreal@gmail.com
}

Desacatos, núm. 44, enero-abril 2014, pp. 9-15 
En este número de Desacatos se explora el fenómeno desde distintos ángulos. Las crisis, los dineros y las deudas involucran de manera central una gama de relaciones sociales que se ponen sobre la mesa para su análisis. Se ha avanzado mucho en el acercamiento teórico y empírico de estos fenómenos en las últimas décadas y se llega a cuestionar la naturaleza misma de los sistemas monetarios. Es en este afán que se retoman escenarios de poblaciones de bajos ingresos en México, la India y Estados Unidos en los que se muestran las sutilezas de las operaciones financieras y el comportamiento de endeudamiento.

\section{LA CRISIS, EL DINERO Y LA DEUDA}

David Graeber - activista destacado del movimiento Occupy Wall Street, profesor del Goldsmiths College en la Universidad de Londres, antropólogo brillante que se dio a conocer gracias a sus teorías innovadoras sobre valor e intercambio- afirma que la crisis financiera de 2008 no sólo ha puesto de manifiesto el coraje y el desconcierto generalizados, sino que constituye el principio de una conversación pública sobre la naturaleza de la deuda, del dinero y de las instituciones financieras que han venido a sostener el futuro de naciones enteras en sus garras. Un factor crítico, dice, es "la capacidad del dinero de convertir la moralidad en una cuestión de aritmética impersonal, y al hacerlo, justificar cosas que de otra manera parecerían atroces u obscenas" (Graeber, 2011). Explica:

En un nivel, la diferencia entre una obligación y una deuda es simple y obvia. Una deuda es la obligación de pagar cierta cantidad de dinero. Como resultado de ello, una deuda, a diferencia de otras formas de obligación, puede ser cuantificada con precisión. Ello permite que las deudas sean simples, frías e impersonales - lo cual, a su vez, las hace transferibles-. Si uno debe un favor, o la vida, a otro ser humano, se debe a esa persona específicamente. Pero si uno debe 40000 dólares al 12\% de interés, en realidad no importa quién sea el acreedor [...] uno no necesita calcular los efectos humanos, sólo requiere calcular el capital, los balances, los recargos y las tasas de interés (Graeber, 2011: 13). ${ }^{1}$

Así, se desembarazan los números de las ciertas relaciones sociales y se insertan en nuevos marcos conceptuales que involucran formas de valoración diversas y nuevos formatos de interacción. Surgen modelos, instrumentos y formas de organización innovadoras para comprender y manipular el mundo en aspectos críticos. Se diseñan novedosas técnicas para calcular el riesgo, lo cual permite que ciertas porciones de la seguridad financiera se trasladen a productos separados y que estas fracciones se combinen en un papel financiero híbrido y complejo (Fisher y Downey, 2006: 9; Forrester, 2000). Joseph Stiglitz, ganador del Premio Nobel de Economía en 2001, afirma que algunos de estos nuevos instrumentos, en particular los Credit Default Swaps (CDs) o permutas de riesgo crediticio, 2 "supuestamente fueron creados para manejar el riesgo pero en realidad fueron diseñados para engañar a los reguladores, y eran tan complejos que de hecho amplificaban el riesgo" (Stiglitz, 2010: XVIII).

Graeber (2011: 15) explica cómo gran cantidad de innovaciones financieras ultrasofisticadas resultaron ser estafas muy complejas. Consistían en operaciones como vender hipotecas a familias pobres, elaboradas de manera que les era inevitable incurrir en cartera vencida, y hacer apuestas sobre el tiempo que tomaría a los dueños de las hipotecas caer en mora. Luego juntaban las hipotecas y las apuestas

\footnotetext{
${ }^{1}$ Simmel ([1907] 1990) acota que la abstracción y el anonimato del dinero liberaron a los humanos de las añejas distinciones de estatus, pero los dejó sin nada más que el dinero para juzgar los mundos sociales y naturales que los rodeaban. También Polanyi ([1944] 2001) explica la "gran transformación" de la separación de la economía de la sociedad.

${ }^{2} \mathrm{El}$ cDs funciona igual que cualquier otro seguro. Durante la duración del bono comprado por el inversionista al gobierno, el asegurado deberá pagar una prima de riesgo determinada al inicio del contrato.
} 
en un solo paquete y las vendían a inversionistas institucionales - que tal vez representaran las cuentas de retiro de los mismos poseedores de las hipotecas- con el argumento de que ganarían dinero independientemente de lo que sucediera. Se permitía a los inversionistas pasar estos paquetes de mano en mano como si fueran dinero. Se traspasaba la responsabilidad de pagar la apuesta a un conglomerado gigante de aseguramiento, que si se hundía bajo el peso de la deuda resultante - lo que seguramente ocurriría - tendría que ser rescatado con los impuestos de los ciudadanos, lo que ciertamente sucedió

Este proceso se documenta en este número de Desacatos, en el artículo de Magdalena Villarreal desde el ángulo de los mexicanos endeudados con hipotecas en California. Se detallan los significados y las fronteras involucrados en las deudas y las obligaciones de quienes viven al mismo tiempo en dos culturas económicas: la estadounidense y la mexicana. Se pone al descubierto la naturaleza social $-\mathrm{y}$ de hecho discriminatoria - de las etiquetas en las que se basaron las hipotecas subpreferenciales (subpri$m e)$ y los marcos ambiguos en los que se decreta la diferencia entre endeudamiento y sobreendeudamiento. Con ello se busca contribuir a desnudar la naturaleza de los sistemas financieros al desandar el camino de desembarazamiento de los números respecto de las relaciones sociales.

$\mathrm{Y}$ es que, si bien podemos afirmar que los mercados y los corporativos están insertos en contextos sociales y que además son "socialmente construidos", es necesario ir más allá para comprender, como afirman Fisher y Downey (2006: 8), que los discursos técnicos y organizativos literalmente forman parte de la composición de mercados y corporativos (Callon, 1998). Como dice Campbell (1987, citado en Fisher y Downey, 2006), desde la Revolución Industrial el capitalismo se ha apoyado tanto en la fundación cambiante de fantasías, deseos y sueños como en los cambios tecnológicos o de las relaciones materiales.

\section{INCLUSIÓN FINANCIERA Y EL ACCESO A UN PEDAZO DE CAPITALISMO}

Ser propietario de una vivienda, un auto y tal vez algunas joyas u objetos de valor es una de las aspiraciones consideradas legítimas por la sociedad. Se asocia con los derechos humanos y políticos que se han ganado a pulso con sudor y luchas sociales. En este contexto, el acceso a un empleo que proporcione ingreso seguro forma parte de estos derechos, lo mismo que ser sujeto de crédito. En su libro The Ascent of Money, Niall Ferguson comenta que la pobreza no es el resultado de la explotación de los sectores pobres de la población por parte de financieros rapaces, sino que tiene mucho más que ver con la falta de instituciones financieras, con la ausencia de bancos y no con su presencia. Sólo hasta que los prestatarios tengan acceso a redes crediticias eficientes podrán escapar de las garras de los usureros y sólo hasta que los ahorradores puedan depositar su dinero en bancos confiables éste podrá ser canalizado de la improductividad a lo industrioso o de los ricos a los pobres (Ferguson, 2009: 15).

Bajo razonamientos como éste el tema de la inclusión financiera ha cobrado gran relevancia a nivel mundial con la anuencia entusiasta de multitudes que han sido etiquetadas como pobres. La posibilidad de "comprar un pedazo del capitalismo" (Graeber, 2011) o lo que algunos han llamado "democratizar las finanzas" implica ya no depender de los renteros, sino constituirse en rentero, empresario e inversionista. De aquí la apuesta por las microfinanzas como herramienta para salir de la pobreza. Así, el proyecto iniciado por Muhammad Yunus a mediados de los setenta, que le hizo acreedor al Premio Nobel de la $\mathrm{Paz}$, ha adquirido gran popularidad. En el Banco Grameen, impulsado por Yunus, se ofrecen préstamos pequeños a personas de bajos recursos para iniciar proyectos productivos sin demandar la garantía de alguna propiedad como colateral. Se apuesta a que la gente utilice sus propios recursos sociales para trabajar el pequeño capital semilla. La 
confianza en la capacidad emprendedora de los beneficiarios y en su responsabilidad para cubrir las deudas es una de las piedras angulares de este sistema, que involucra inversión en términos sociales: participación activa en asambleas, talleres y capacitaciones. El sistema funciona con base en grupos. Todos los miembros deben solicitar un monto de manera regular y todos son responsables por el crédito total del grupo. Yunus (2007) considera que las microfinanzas tienen el potencial de crear un "mundo sin pobreza", a través de lo que él llama "negocios sociales", los cuales, argumenta, son una forma más humana del capitalismo. Collins et al. (2009: 24) documentan que para 2006 el Banco Grameen proporcionaba servicios a más de seis millones de clientes de sectores de bajos recursos en distintos poblados de Bangladesh. El modelo se replicó en la India y entre ambos alcanzaron 10 millones de clientes en 2007, lo que representó un incremento de 3.1 millones respecto del año anterior. El sistema ha sido retomado por múltiples organizaciones en varios países. En México existen bancos Grameen en algunos estados de la república, además de numerosos microbancos que siguen este patrón.

Lourdes Angulo Salazar analiza casos de microbancos en Oaxaca, en particular en relación con las implicaciones sociales de este tipo de organización, y contrasta la experiencia con cajas populares en el Valle de Autlán-El Grullo, en Jalisco. A diferencia de los microbancos, las cajas populares funcionan con ahorros de los socios y los préstamos no requieren colateral, pero sí aval. Fueron introducidas a México a mediados del siglo xx por la Iglesia católica. Sus antecedentes datan de mediados del siglo XIX en Alemania con las Cajas Raiffeisen, las cuales consistían en sistemas cooperativos de ahorro y crédito basados en principios de autoayuda (Vizcarra, 2004: 288-290).

Gabriela Guzmán Gómez se enfoca en una caja popular de mujeres en Veracruz, detalla los aprendizajes y los problemas que enfrentan sus socias en el afán de convertirse en pequeñas empresarias. Señala las consecuencias que sobrevienen tras lo que considera una sobreoferta de créditos, en particular de microfinancieras comerciales. A pesar de que la idea de las microfinanzas se asocia sobre todo a la promoción de empresarialidad con el objetivo de ayudar a la gente a comprar bienes productivos y material de trabajo para iniciar sus negocios, éste no siempre es el caso. Y es que, como aseguran Collins et al. (2009: 25), es importante tomar en cuenta que los hogares pobres buscan préstamos para una multiplicidad de fines, además de inversión en negocios: enfrentar emergencias, adquirir bienes para el hogar, pagar cuotas educativas y de salud, y en general maniobrar mejor sus complicadas vidas. Es decir, con frecuencia se canaliza el microcrédito de sus usos intencionados a otros que resultan de mayor importancia para los hogares. Los autores preconizan que las microfinanzas pueden ayudar a mejorar el manejo presupuestal de los pobres y, por tanto, sus vidas cotidianas. Opinan que deben desarrollarse microfinanzas para el consumo, no sólo para generar actividades productivas, puesto que es una excelente oportunidad para "abrir el mercado más grande que se pueda encontrar entre los pobres" (Collins et al., 2009: 180)

Pero la idea de que los pobres son susceptibles a bancarización atrae a inversionistas de distintos niveles, de modo que la gama de microfinancieras privadas ha crecido de forma exponencial, a la par de las iniciativas gubernamentales y no gubernamentales en este sentido. Aunque a decir de algunos analistas el acceso a servicios financieros es insuficiente y aún quedan muchas áreas por cubrir, no es claro que los resultados de las microfinancieras lleven a salir de la pobreza. Lo que sí es evidente es que algunas han logrado ganancias que causarían envidia a los banqueros de Wall Street.

En muchas localidades la oferta de microcrédito es tal que los prestatarios consiguen dinero de una microfinanciera para pagar a otra, y de una tercera para pagar a la segunda, hasta caer en una espiral de deuda que hace peligrar su estabilidad económica y social. Esto último debido a la presión social ejercida por los grupos que reciben el préstamo, en otros casos por los avales o simplemente por la 
preocupación de no ser elegibles para otro crédito por no pagar. Esto se ha convertido en parte indispensable de su supervivencia. Para bien o para mal, han comprado un pedazo del pastel capitalista con todo y sus contradicciones, crisis y dilemas, y la necesidad generada de mayor inclusión financiera persiste.

\section{SOBREENDEUDAMIENTO}

Lourdes Angulo y Gabriela Guzmán comparten la preocupación por la situación de extrema vulnerabilidad en que se colocan las familias de bajos recursos. Guzmán destaca que las mujeres han tenido que vender activos para cubrir sus deudas, proceso también retratado en el texto de Guérin, Roesch, Venkatasubramanian y Kumar para el caso de la India, en el que los autores presentan un estudio exhaustivo de una zona rural del sur de este país y detallan el empobrecimiento que han causado los procesos de endeudamiento y sobreendeudamiento en las familias. Hacen énfasis en la manera en que las deudas se forjan al calor de relaciones y jerarquías sociales, que son tan importantes como los criterios financieros. Guérin, Roesch, Venkatasubramanian y Kumar insisten en que detrás de este problema hay más que la victimización de los pobres y argumentan que la definición de sobreendeudamiento no puede restringirse a los procesos de deterioro y extracción de bienes materiales.

El término sobreendeudamiento es relativamente nuevo en los sectores de bajos recursos. Como hemos indicado en otras ocasiones (Villarreal, 2000), la gente se refiere a "drogas" o "compromisos" cuando la deuda es pesada, pero el límite entre estar endeudado y sobreendeudado se define en interacción social, en la que se atribuyen etiquetas y se asocian riesgos a ellas. Hasta hace poco, las etiquetas de sobre y subendeudamiento se constreñían al ámbito de las finanzas en las empresas, los corporativos y las naciones. Se considera el subendeudamiento, por ejemplo, como muestra de que no se utilizan los recursos de manera eficiente para maximizar su capacidad de ganancia, en tanto que la etiqueta de sobreendeudamiento conlleva una connotación de desconfianza hacia alguien que no supo manejar sus finanzas de manera adecuada. Dentro de una y la misma relación el endeudamiento puede concebirse como un recurso, como riqueza virtual, como un compromiso o un mecanismo para la reproducción de vulnerabilidad y falta de poder. Tanto Villarreal como Guérin y colaboradores constatan la manera en que las categorías sociales, las jerarquías y las relaciones de poder intervienen en los criterios para definir la capacidad de pago de los clientes.

En los sectores de bajos recursos, la utilización de la etiqueta de sobreendeudamiento proviene de los ámbitos microfinancieros. Se trasladan criterios e interpretaciones de los sectores bancarios con el propósito de mitigar el riesgo. Angulo analiza los mecanismos de cobranza que han adoptado las microfinancieras a la luz de las crecientes dificultades de sus clientes para pagar. Examina las implicaciones del uso de tales mecanismos, en particular en el empleo de relaciones sociales como colateral social. Estos procesos inciden negativamente en las buenas relaciones que pudieran tener los clientes en sus vecindarios y sus redes familiares. Ello apunta a la noción de capital social, la cual se ha utilizado para designar los elementos sociales y simbólicos que forman parte de las transacciones económicas. Éstos no pueden simplemente acumularse, sino que se potencian en las relaciones sociales. En el mundo de hoy, en el que la información y las especulaciones respecto del futuro constituyen parte del capital, los vínculos sociales y la confianza juegan un papel fundamental.

Así, el sobreendeudamiento puede tomar distintas formas, desde la seguridad de un empleo, como veremos más adelante, hasta la pérdida material, la movilidad social descendente, la humillación y la vergüenza. Los procesos por medio de los cuales se juzga diferencialmente una capacidad de pago o un estado de endeudamiento tienen que ver no sólo con asimetrías de información, como suele afirmarse en los 
textos de economía. No es sólo que algunos de los participantes "carezcan de información", sino que interactúan en espacios en los que se define la lente a utilizar, lo que genera interpretaciones y prioridades diferenciadas. Influyen aquí las posiciones sociales en las que se facilitan o restringen ciertos márgenes de cálculo socialmente construidos.

\section{ENDEUDAMIENTO, LIBERTAD Y DEMOCRACIA}

También en este número de Desacatos, David Picherit analiza el trabajo atado a deudas en el sur de la India. Resalta la perspectiva de los trabajadores ante la seguridad del empleo y el endeudamiento, detalla las condiciones cambiantes de sus labores y las dinámicas de poder que se generan. Se enfoca en trabajadores que deben migrar para trabajar, analiza la complejidad involucrada en las prácticas cotidianas entre los peones atados a deudas y sus empleadores, que incluye la necesidad de retener un empleo seguro y la obligación moral de pagar, pero también la ausencia de protección estable y el quebranto eventual de estatus.

En México, en particular en zonas rurales, la gente aún recurre a los "patrones" para solicitar préstamos a cambio de trabajo y el pago adelantado es, en ocasiones, considerado una bendición (Villarreal, 2000). A menudo es costoso, pero los trabajadores están dispuestos a pagar el precio dada la urgente necesidad de efectivo. Esto puede llevar a formas de trabajo atado y control sobre las opciones y tiempo de los empleados, aunque el grado al que son capaces de negociar los términos de la relación varía. Un trabajador se esforzará para pagar el préstamo rápidamente para liberarse de la deuda y estar en libertad de comprometerse en otras opciones laborales o pudiera preferir pagar lentamente y así asegurar un empleo durante un periodo más largo. En algunos casos, los términos del pago del préstamo permanecen vagos: el patrón no especifica si cobrará intereses ni los tiempos en que la deuda debe ser cubierta. Esto le compra tiempo para juzgar la habilidad y el compromiso del trabajador con el empleo antes de tomar una decisión definitiva sobre cómo reclamará el pago. El trabajador, por su parte, tampoco presionará para aclarar los términos del pago, con la esperanza de que si se gana el favor del patrón el préstamo tal vez quede en el olvido. Mientras, buscará claves en la actitud del patrón o en sus respuestas a otros casos para anticipar la ruta que se tomará y actuar en concordancia. Si se espera un arreglo pesado, el trabajador hará lo posible por pagar rápidamente y salir de la situación, lo cual no siempre es fácil o posible. Con frecuencia se sigue buscando la salida "al norte" para pagar deudas adquiridas durante la enfermedad, por la muerte de un familiar o por una mala cosecha. Por un lado, las instituciones microfinancieras han venido a solventar algunos de estos problemas, y por otro, a causarlos, pues en ocasiones es la deuda con la microfinanciera la que se intenta saldar mediante migración o préstamos de los patrones.

Podemos afirmar, con Graeber (2011), que el trabajo atado a deudas continúa siendo el principio central en el reclutamiento de trabajadores a nivel global, tanto en el sentido literal, como ocurre con frecuencia en el este de Asia o en América Latina, como en el sentido subjetivo, en tanto que la mayoría de quienes trabajan por pago o incluso por un salario sienten que lo hacen fundamentalmente para cubrir préstamos con interés. Pero más allá de esto, si bien antes los ricos eran considerados los mayores acreedores en el mundo, ahora la situación va a la inversa. En esta era de bancos de hipotecas, seguros de vida, beneficios de seguridad social, bancos de ahorro y compra-venta de bonos hay masas de personas con ingresos moderados que son más bien los prestamistas. Los ricos, con sus compañías apalancadas, son ahora los principales deudores. Así parece funcionar la "democratización de las finanzas". 


\section{BIBLIOGRAFÍA}

Callon, Michael, 1998, The Laws of the Markets, Blackwell Publishers, Oxford.

Campbell, Collin, 1987, The Romantic Ethic and the Spirit of Capitalism, Blackwell, Oxford.

Collins, Daryl et al., 2009, Portfolios of the Poor. How the World's Poor live on $\$ 2$ a Day, Princeton University Press, Princeton y Oxford.

Ferguson, Niall, 2009, The Ascent of Money. A Financial History of the World, Penguin Books, Londres.

Fisher, Melissa S. y Greg Downey (eds.), 2006, Frontiers of Capital. Ethnographic Reflections on the New Economy, Duke University Press, Durham y Londres.

Forrester, Viviane, 2000, El horror económico, Fondo de Cultura Económica, México.

Graeber, David, 2011, Debt: The First 5000 Years, Melville House Publishing, Nueva York.

Polanyi, Karl, [1944] 2001, The Great Transformation: The Political and Economic Origins of Our Time, Beacon Press, Boston.
Simmel, George, [1907] 1990, Philosophy of Money, Routledge, Londres.

Stiglitz, Joseph E., 2010, Free Fall. America, Free Markets, and the Sinking of the World Economy, W. W. Norton and Company, Nueva York y Londres.

Villarreal, Magdalena, 2000, "Deudas, drogas, fiado y prestado en las tiendas de abarrotes locales", en Desacatos. Revista de Antropología Social, núm. 3, México.

Vizcarra, Roberto, 2004, "El movimiento social de los ahorradores defraudados por cajas populares en México", en Magdalena Villarreal, Antropología de la deuda. Crédito, ahorro, fiado y prestado en las finanzas cotidianas, Centro de Investigaciones y Estudios Superiores en Antropología Social, Porrúa, Cámara de Diputados, México, pp. 287-312.

Yunus, Muhammad, 2007, Creating a World Without Poverty. Social Business and the Future of Capitalism, $\mathrm{Pu}-$ blic Affairs, Nueva York. 